\title{
A comparative trial of xenon arc and argon laser photocoagulation in the treatment of proliferative diabetic retinopathy
}

\author{
A. P. Plumb, A. V. SWAN, A. H. Chignell, and J. S. SHilling \\ From the Ophthalmic Department, St Thomas's Hospital, London SE1 7EH
}

SUMMARY We present the results of a randomised study comparing xenon arc and argon laser photocoagulation in the treatment of proliferative diabetic retinopathy. Our results show that when used in the way described below there is no significant difference between the effect of the 2 treatments on optic disc neovascularisation and visual acuity. We also compare the results of peripheral retinal ablation with those of panphotocoagulation in the argon and xenon groups. The results suggest that in some patients peripheral treatment may be sufficient to cause regression of disc neovascularisation.

Retinal photocoagulation was introduced by MeyerSchwickerath but was used initially with little effect on diabetic retinopathy.' The first functioning laser was introduced by Maiman ${ }^{2}$ and used to treat the eye by Zanet $e t a l .{ }^{34}$ and Koester $e t a l .{ }^{5}$ Initially the ruby laser was used to treat retinal lesions, but this was superseded by the argon laser ${ }^{6}$ and used by Zweng to treat diabetic retinopathy. ${ }^{7}$ Panphotocoagulation was first described by Aiello ${ }^{8}$ using the ruby laser.

There have been 4 previous studies comparing the effects of argon laser and xenon arc photocoagulation. Fankhauser et al. ${ }^{9}$ used long-duration argon treatment $(0.25-1.5 \mathrm{~s})$ and found little difference between argon and xenon. McLean ${ }^{10}$ compared the side effects of the 2 treatments and found a higher incidence of field loss with xenon, but did not comment on the relative effectiveness of the 2 treatments.

The Diabetic Retinopathy Research Group in America ${ }^{112}$ conducted a multicentre controlled trial on 1727 patients, randomly allocating one eye to the treatment group and one eye as control. The patient was then randomly allocated to an argon or xenon treatment group. The study showed a greater incidence of field loss and visual acuity loss with xenon. In the later report they showed a greater treatment effect with xenon at 2 and 3 years. However, they were unable to apply the standard statistical methods because of multiple response

Correspondence to Dr A. P. Plumb. variables in several subgroups, making exact $p$ values impossible to obtain. But the results did suggest that there was an early increased reduction of visual acuity with xenon in comparison with argon and the control group (in the first 6 weeks), and at a later stage loss of visual acuity was higher in the untreated group, with fewer patients having visual acuities of less than 5/200 in the xenon than the argon groups. Crick et al. ${ }^{13}$ compared the effects of the 2 treatments on visual function in a total of 26 eyes and also the patients' preference. Xenon arc had a greater adverse effect on the peripheral field, and small reductions in visual acuity were more common with xenon. However, the effect on central fields, colour vision, and macular threshold was essentially the same. The difference in the effect of treatment on the prognosis of proliferative retinopathy and the extent of the side effects is presumably related to the extent of retinal damage caused by the 2 treatments.

Wallow and Davis ${ }^{14}$ compared the post-mortem appearance of argon and xenon burns, and demonstrated that much deeper burns were caused by xenon arc. Two-thirds thinning of the retina was seen with all xenon burns, whereas this was seen only in argon treatment of longer duration $(0 \cdot 5 \mathrm{~s})$. Other studies of interest include a 3-year study of peripheral retinal ablation with argon, ${ }^{15}$ which showed a significantly better response for visual acuity in treated eyes. In 1977 a multicentre randomised controlled trial on the effect of xenon arc photocoagulation ${ }^{16}$ showed a greater deterioration in the untreated eye at 
1,2 , and 3 years after treatment when patients had disc neovascularisation, but there was no significant difference if only peripheral new vessels were present. There was a greater response in the treated than untreated eyes. Oosterhuis ${ }^{17}$ reported the results of a carefully designed trial of the effects of focal retinal treatment with the xenon arc photocoagulator which showed a decrease in proliferation in treated eyes. This study is interesting because it included a period of study to assess the change of the retinopathy before treatment was begun.

A recently published study ${ }^{1819}$ compared the effect of xenon arc and argon laser in the treatment of disc neovascularisation in 21 patients and found no difference in the effect on disc vessels and visual acuity, but there was greater functional loss after xenon treatment.

\section{Patients and methods}

Sixty-three patients attending the St Thomas's Hospital Diabetic Retinopathy Clinic who had optic disc neovascularisation were selected for participation in the trial. No exclusion was made on the grounds of type or degree of diabetic control, though patients were included only if the following criteria in the examined eye were met with: (1) no previous photocoagulation; (2) no retinal detachment and not more than a minor degree of retinitis proliferans; (3) absence of rubeosis or glaucoma; (4) media clear enough to allow adequate photocoagulation. In 17 patients both eyes were entered into the trial and each eye was randomly allocated to a treatment group.

At the beginning of the study eyes were randomly allocated to an argon laser or xenon arc treatment group. At a later stage we decided to investigate the effect of incomplete retinal photocoagulation, as it seemed likely that some patients might benefit from peripheral treatment only. Therefore patients were then allocated to an argon laser group or xenon arc group and further allocated to a total or peripheral treatment group. 'Peripheral' treatment was the area treated by the contact lens mirror (peripheral zone in diagram). 'Total' treatment was the usual panretinal photocoagulation (intermediate and peripheral zone. Fig. 1).

RETINAL TREATMENT AREAS

There were therefore 6 groups in all: the original argon laser and xenon arc groups and subsequently the 4 subgroups: argon total, argon peripheral, xenon total, and xenon peripheral. Argon laser treatment was administered via a 3-mirror contact lens after topical application of a local anaesthetic. Xenon arc treatment was administered after a retrobulbar injection of $2 \%$ lignocaine. Some patients receiving argon laser treatment required a retrobulbar injection of lignocaine if the treatment became painful. Argon laser treatment was delivered by a Coherent Radiation System 800 argon laser with $0 \cdot 1-0 \cdot 2$ second duration and a $500 \mu \mathrm{m}$ burn size. Xenon treatment was delivered by the O'Malley Log 2 xenon arc photocoagulator with up to $1 \cdot 0$ second burn duration and $4.5^{\circ}$ cone size (the end point of treatment was taken as the first sign of retinal whitening). Xenon treatment was usually given in 2 sessions. Argon treatment was given in 2 to 4 sessions.

The results of treatment are based on recordings before beginning therapy, and the follow-up period is dated from the completion of treatment (in the 'total' treatment area groups no further therapy was given in the follow-up period). The results of treatment were recorded on a proforma, which included details of corrected visual acuity and a grading of the retina and disc new vessels according to the Hammersmith method. ${ }^{20}$

The response to treatment was determined by observing the visual acuity and grading of new vessels on the disc over a period of 2 years after treatment. To compare the treatment it was then necessary to assess how the trends in visual acuity (on a scale of 1 to 9: $6 / 5$ to $<6 / 60$ ) and disc grading (on a scale of 1 to 5 ) differed over time. In the analysis each subject was allowed to have his own pattern of response over time and then the average difference between the treatment groups was assessed. This was done after taking into account factors which might influence response.

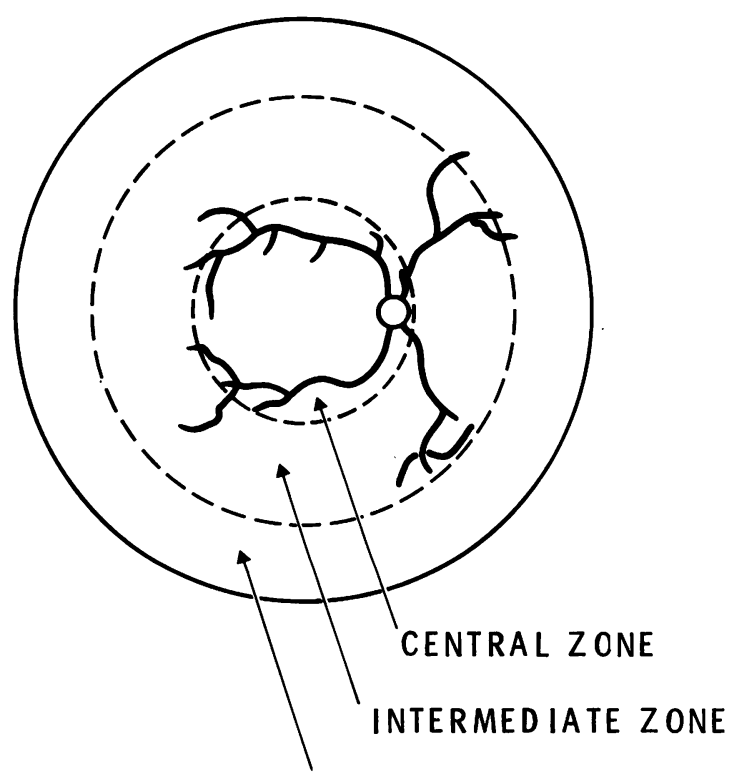

PER I PHERAL Z ONE

Fig. 1 Photocoagulation treatment areas. 
Table 1 Average duration of diabetes before treatment according to age of onset of diabetes

\begin{tabular}{llll}
\hline $\begin{array}{l}\text { Age of onset } \\
\text { (vears) }\end{array}$ & No. & $\begin{array}{l}\text { Mean duration of } \\
\text { diabetes before } \\
\text { treatment (vears) }\end{array}$ & $\begin{array}{l}\text { Range } \\
\text { (vears) }\end{array}$ \\
\hline $1-20$ & 21 & 22 & $7-38$ \\
$21-40$ & 18 & 18 & $1-35$ \\
$41-60+$ & 22 & 6 & $1-22$ \\
\hline
\end{tabular}

Table 2 Length of follow-up in all treatment subgroups

\begin{tabular}{lll}
\hline & Range (months) & $\begin{array}{l}\text { Average follow-up } \\
\text { (months) }\end{array}$ \\
\hline Xenon & $2-40$ & 22 \\
Xenon periphery & $1-22$ & 9 \\
Xenon total & $1-40$ & 17 \\
Argon & $1-47$ & 20 \\
Argon periphery & $2-32$ & 12 \\
Argon total & $1-36$ & 14 \\
\hline
\end{tabular}

Table 3 Number of eves in each treatment group at the beginning and end of study (after 2 years of follow-up)

\begin{tabular}{lrrrr}
\hline & \multicolumn{2}{c}{ Baseline } & \multicolumn{2}{c}{ End of studv } \\
& $V A$ & $N V D$ & $V A$ & $N V D$ \\
\hline Xenon & 19 & 19 & 7 & 10 \\
Xenon peripheral & 9 & 9 & 2 & 3 \\
Xenon total & 12 & 12 & 6 & 6 \\
Argon & 16 & 16 & 8 & 7 \\
Argon peripheral & 13 & 13 & 3 & 3 \\
Argon total & 11 & 11 & 4 & 4 \\
Total & 80 & 80 & 30 & 33 \\
\hline
\end{tabular}

$\mathrm{VA}=$ visual acuity. $\mathrm{NVD}=$ new vessels on disc.

Table 4 'Peripheral' treatment patients given additional treatment

\begin{tabular}{ll}
\hline $\begin{array}{l}\text { Peripheral treatment } \\
\text { group }\end{array}$ & No. of eves \\
\hline Xenon & 4 \\
Argon & 5 \\
\hline
\end{tabular}

Table 5 Visual acuity $(-=$ deterioration; $+=$ improvement)

\begin{tabular}{lccccc}
\hline Treatment & \multicolumn{1}{l}{$\begin{array}{l}\text { Initial } \\
\text { No. of eves }\end{array}$} & \multicolumn{5}{c}{ Time interval (months) } \\
\cline { 3 - 7 } & & $0-3$ & $3-6$ & $6-12$ & $12-24$ \\
\hline Xenon & 19 & $-1 \cdot 1$ & $-0 \cdot 2$ & $-0 \cdot 4$ & $-0 \cdot 8$ \\
Xenon peripheral & 9 & $+0 \cdot 3$ & $-0 \cdot 5$ & $-0 \cdot 6$ & $+0 \cdot 3$ \\
Xenon total & 12 & $-0 \cdot 4$ & $-0 \cdot 9$ & $-0 \cdot 7$ & $-1 \cdot 2$ \\
Argon & 16 & $+0 \cdot 1$ & $-0 \cdot 1$ & $-0 \cdot 4$ & $-0 \cdot 2$ \\
Argon peripheral & 13 & $-0 \cdot 2$ & $0 \cdot 0$ & $+0 \cdot 4$ & $+0 \cdot 2$ \\
Argon total & 11 & -0.8 & $+0 \cdot 5$ & $-0 \cdot 8$ & -0.3 \\
\hline
\end{tabular}

Table 6 Optic disc neovascularisation based on a grading system $1-5^{20}(-=$ deterioration, $+=$ improvement $)$

\begin{tabular}{lrrrrr}
\hline Treatment & \multicolumn{4}{l}{$\begin{array}{l}\text { Initial } \\
\text { No. of eves }\end{array}$} & \multicolumn{4}{c}{ Time interval (months) } \\
\cline { 3 - 6 } & & $0-3$ & $3-6$ & $6-12$ & $12-24$ \\
\hline Xenon & 19 & $+1 \cdot 2$ & $+1 \cdot 0$ & $+1 \cdot 5$ & $+1 \cdot 5$ \\
Xenon peripheral & 9 & $+1 \cdot 1$ & $+1 \cdot 2$ & $+1 \cdot 4$ & $+1 \cdot 6$ \\
Xenon total & 12 & +0.9 & $+1 \cdot 0$ & $+1 \cdot 6$ & $+1 \cdot 6$ \\
Argon & 16 & $+0 \cdot 9$ & $+0 \cdot 8$ & $+0 \cdot 6$ & $+1 \cdot 0$ \\
Argon peripheral & 13 & $+1 \cdot 0$ & $+0 \cdot 4$ & $+1 \cdot 5$ & $+2 \cdot 0$ \\
Argon total & 11 & $+0 \cdot 8$ & $+1 \cdot 7$ & $+1 \cdot 7$ & $+1 \cdot 1$ \\
\hline
\end{tabular}

for example, age, sex, and duration of diabetes. The analysis was performed with the statistical program GLIM $^{21}$ with the facilities of the London University Computer Centre.

The 63 patients involved in the study ranged in age from 21 to 74 years (mean 47.5 years), and the duration of diabetes (from diagnosis to date of first treatment) varied from less than a year to 38 years (mean $14 \cdot 2$ years). The average duration of diabetes before treatment in the juvenile diabetic group (under 41 years) was 20 years and in the group aged over 40 was 6 years (see Table 1). There were 37 male $(58.7 \%)$ and 26 female patients $(41.3 \%)$.

The maximum follow-up time in the xenon arc groups was $\mathbf{4 0}$ months and in the argon laser groups was 47 months (see Table 2 for range and average follow up time in each treatment group). The number of eyes assessed in each subgroup at the beginning and end of the study is given in Table 3.

\section{Results}

INADEQUATE TREATMENT RESPONSE

It was decided when following up patients that if a complete regression of disc neovascularisation was not achieved from peripheral treatment then further treatment of the same type would be given in the intermediate zone, and observation was continued to determine the effect of this delay in completing panretinal photocoagulation (Table 4). Patients who received further treatment of a different type were withdrawn from the study.

Table 5 shows the average change in visual acuity (lines on the Snellen chart) when compared with the pretreatment value in the 6 subgroups at various time intervals. There is no clear pattern, but since the number of individuals observed at each time interval was variable the picture may be misleading. This also applies to the results shown in Table 6 (disc neovascularisation based on Hammersmith grading code). Therefore regression analysis was performed allowing for this problem while estimating the average trend in each group by the GLIM statistical program. 


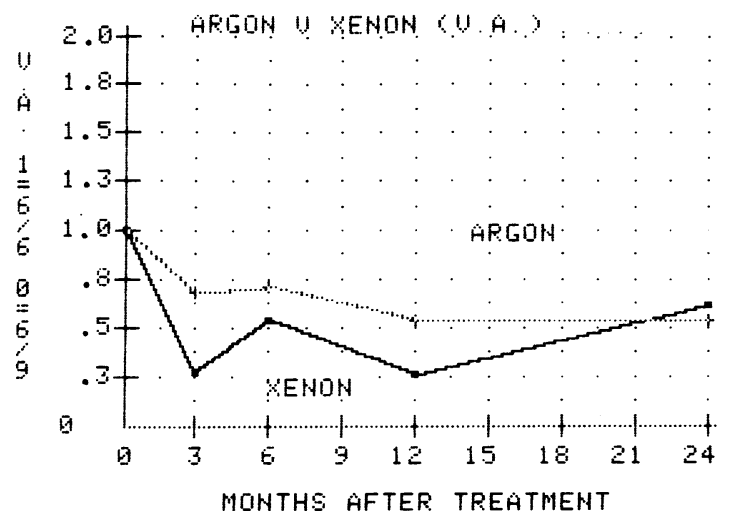

$\begin{array}{lcl} & \text { PLOT 1 (5 PTS) } \\ \text { POINT\# } & \text { X(I) } & \text { Y(I) } \\ 1 & 0 & 1 \\ 2 & 3 & 0 \cdot 27 \\ 3 & 6 & 0 \cdot 53 \\ 4 & 12 & 0 \cdot 26 \\ 5 & 24 & 0.61\end{array}$

Fig. 2 A comparison of argon laser and xenon arc photocoagulation; average change of visual acuity over 2 years.

The regression analysis used assumes that the response variables for visual acuity and optic disc neovascularisation were normally distributed. Obviously with integer codes this cannot be the case. Nonetheless the variation about the trends fitted in the analysis was found to be sufficiently close to normal for present purposes.

\section{REGRESSION ANALYSIS:}

ARGON LASER VERSUS XENON ARC

All results are based on the comparison of the treatment groups followed up for 2 years. The period of follow-up dates from the last day of the treatment course; no further treatment was given during this period.

\section{VISUAL ACUITY}

On comparison of argon laser and xenon arc panretinal photocoagulation no significant difference in the effect on visual acuity was noted. Fig. 2 shows the average trend in visual acuity over 2 years for each treatment type, estimated from the regression model that would be expected from a hypothetical ' $6 / 6$ ' eye (NB: it is the nonparellelism between the 2 treatments and the difference thus shown which are important rather than the absolute visual acuities). All 4 graphs in this section are plotted by a similar method.

NEW VESSELS ON THE DISC

Xenon arc treatment produced an average improvement of 1.5 grades at 24 months; the response to

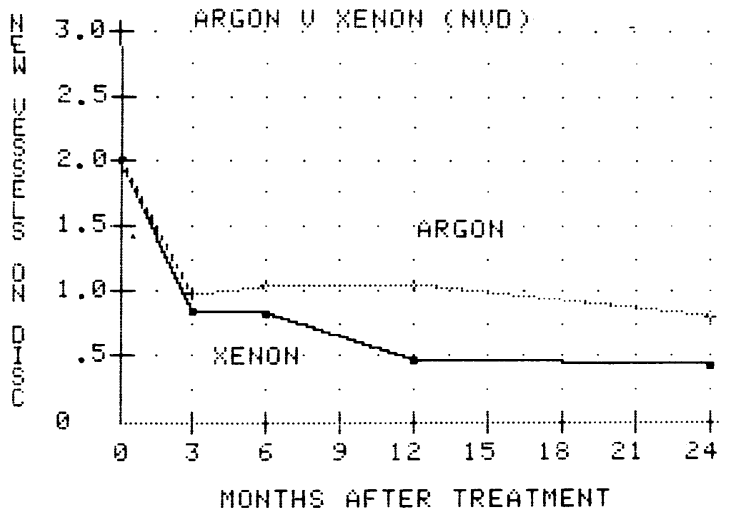

\begin{tabular}{|c|c|c|}
\hline \multicolumn{3}{|c|}{ PLOT I (5 PTS) } \\
\hline DINT\# & $X(I)$ & $Y(I)$ \\
\hline & 0 & 2 \\
\hline & 3 & $0 \cdot 84$ \\
\hline & 6 & $0 \cdot 83$ \\
\hline & 12 & $0 \cdot 46$ \\
\hline
\end{tabular}

\begin{tabular}{lll}
\multicolumn{4}{c}{ PLOT 2 (5 PTS) } \\
POINT\# & $X(\mathrm{I})$ & $\mathrm{Y}(\mathrm{I})$ \\
1 & 0 & 2 \\
2 & 3 & $0 \cdot 99$ \\
3 & 6 & $1 \cdot(14$ \\
4 & 12 & $1 \cdot(14$ \\
5 & 24 & $0 \cdot 8$
\end{tabular}

Fig. 3 Comparison of argon laser and xenon arc photocoagulation; average change of disc neovascularisation over 2 vears.

argon was an improvement of one grade at 24 months. However, this difference did not reach statistical significance. Fig. 3 gives the estimated average response to treatment over time for a hypothetical eye with an initial new vessel grading of 2 .

This shows that most of the response occurs in the first 3 months and is almost identical for both treatments, so there is little to choose between them in the speed of response. There is only a slight improvemont over the subsequent 21 months.

This is a regression model based on a hypothetical eye and therefore the fact that the graph does not reach zero at 24 months does not necessarily mean that complete regression of disc vessels was not achieved in the majority of cases. In fact only 6 patients failed to respond completely (see Table 7). This failure to respond was defined as the presence of

Table 7 Analysis of patients with an inadequate response

\begin{tabular}{lllllll}
\hline Treatment & Sex & Age & $\begin{array}{c}\text { Duration of Initial } \\
\text { diabetes }\end{array}$ & $\begin{array}{l}\text { Final } \\
\text { NVD }\end{array}$ & $\begin{array}{l}\text { Time } \\
\text { interval } \\
\text { (months) }\end{array}$ \\
\hline Argon & F & 34 & 6 months & 3 & 1 & 40 \\
Argon & M & 52 & 7 months & 2 & 1 & 34 \\
Argon & F & 47 & 13 years & 2 & 2 & 12 \\
Xenon & F & 52 & 14 years & 2 & 1 & $* 31$ \\
Xenon & M & 56 & 18 months & 3 & 1 & 40 \\
Xenon & F & 46 & 2 years & 5 & 1 & 34 \\
\hline
\end{tabular}

*This patient received argon treatment at this stage.

NVD $=$ new vessels on disc. 


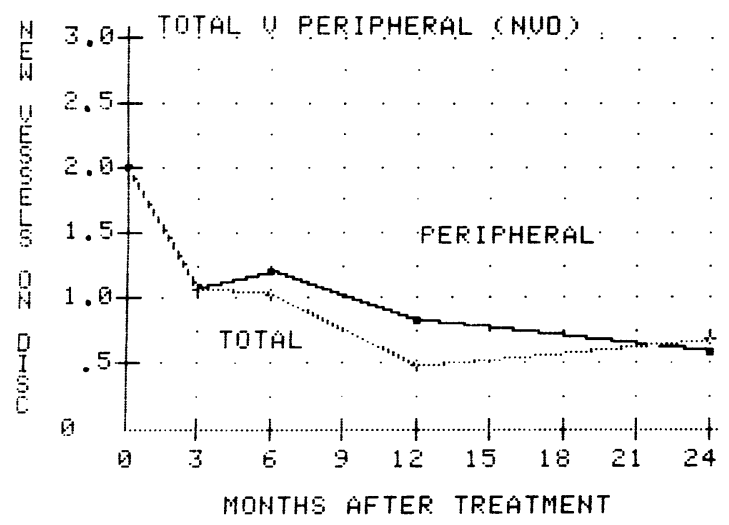

\begin{tabular}{lcl}
\multicolumn{4}{c}{ PLOT 1 (5 PTS) } \\
POINT\# & X(I) & Y(I) \\
1 & 0 & 2 \\
2 & 3 & $1 \cdot 08$ \\
3 & 6 & $1 \cdot 21$ \\
4 & 12 & $0 \cdot 82$ \\
5 & 24 & 0.59
\end{tabular}

\begin{tabular}{lcl}
\multicolumn{3}{c}{ PLOT 2 (5 PTS) } \\
POINT\# & X(I) & Y(I) \\
1 & 0 & 2 \\
2 & 3 & $1 \cdot 06$ \\
3 & 6 & $1 \cdot 03$ \\
4 & 12 & $0 \cdot 49$ \\
5 & 24 & $0 \cdot 69$
\end{tabular}

Fig. 4 Comparison of total and peripheral treatment areas; average change in disc neovascularisation over 2 years.

disc vessels at least 12 months after the initial treatment course.

The main similarities between these patients are that their age of onset of diabetes falls in the range 30-50+ years, and they all had fairly marked disc neovascularisation when treatment was started.

COMPARISON OF PERIPHERAL AND TOTAL GROUPS Since no significant difference between the argon and xenon treatments was noted, the different treatments were combined to determine the difference, if any, between the effect of treating the retinal periphery only and a standard panphotocoagulation. The pattern of response estimated from the regression model is shown in Figs. 4 and 5 . In neither case was the difference significant, though there was a slight suggestion that peripheral treatment produced better visual acuity results. This result occurs partly because there was a farily high incidence of withdrawal of patients (13 out of 22) who were unsatisfactorily responding to peripheral treatment. Therefore towards the end of the 2-year period the peripheral group consisted of a selected group of good responders.

An analysis of the cases withdrawn from this part of the study was performed. Of a total of 22 peripherally treated patients 13 were given extra treatment or withdrawn. These were compared with those remaining in the study. There was no significant difference in visual acuity, disc neovascularisation grading, retinal grading, and mean age between the

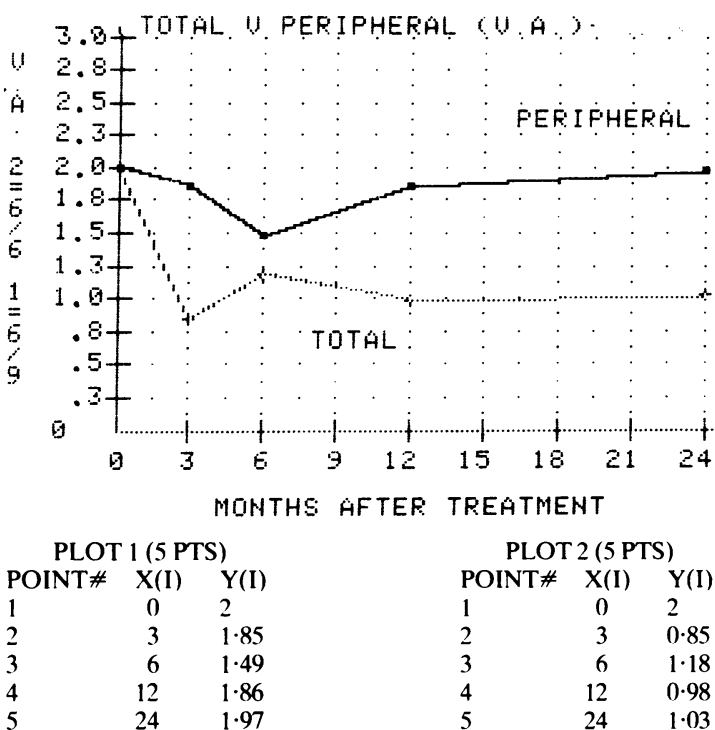

Fig. 5 Comparison of total and peripheral areas of treatment; average change in visual acuity over 2 years.

groups. Of these patients 9 received further treatment of the same type; 4 xenon group patients improved on average by one disc grading during the period after extra treatment. Five patients in the argon laser group showed on average no changes in disc grading after further treatment.

\section{Discussion}

The main conclusion from this trial is that, when they are used with the technique described above, there is little to choose between argon laser and xenon arc in their effectiveness. Xenon arc treatment appears to be slightly more effective, but the difference is not statistically significant Fig. 3 .

The results obtained when comparing the peripheral and total treatment groups suggest that there may be a case, in suitable patients, for initially treating the peripheral area only, and only at a later stage 'filling in' the central area if neovascularisation occurs. However, on comparison of the group of patients who responded well to peripheral treatment with those who did not respond there was no way of predicting the outcome of treatment from the initial fundus examination or other patient characteristics. Furthermore after further treatment to the intermediate zone, i.e., to complete the panphotocoagulation, the response has not been completely satisfactory. Whether this means that delaying the full panphotocoagulation is detrimental to the outcome or whether these are patients who do not 
respond particularly well to treatment is not clear. It does suggest that at present the safest course is probably to pursue a technique of complete panphotocoagulation from the outset.

\section{CONCLUSIONS}

We have shown that there is no significant difference between the 2 treatments in the effect on visual acuity and disc neovascularisation and that treatment of the peripheral retina only is inadequate in many cases of proliferative retinopathy. Previous studies have shown a higher incidence of visual field loss and difficulty with night vision with xenon arc. ${ }^{10-13}$ Therefore it appears that these factors should be the main deciding points when contemplating the choice of photocoagulator in the treatment of proliferative diabetic retinopathy.

We are grateful to Mrs Margaret Grice for her secretarial assistance. Dr A. P. Plumb is an Iris Fund research fellow.

\section{References}

1 Meyer-Schwickerath G. Light Coagulation. Transl. Drance S. St Louis: Mosby, 1959: 75.

2 Maiman TH. Stimulated optical radiation in the ruby. Nature $1960 ; 187: 493-4$.

3 Zaret MM, Ripps H, Siegel IM, Breinin GM. Laser photocoagulation of the eye. Arch Ophthalmol 1963; 69: 97-104.

4 Zaret MM, Ripps H, Siegel IM, Breinin GM. Biomedical experimentation with optical masers. J Opt Soc Am 1962; 52: 607 (abstr).

5 Koester CJ, Snitzer E, Campbell CJ, Rittler MC. Experimental laser retina coagulator. J Opt Soc Am 1962; 52: 607 (abstr).

6 L'Esperance FA Jnr. An ophthalmic argon laser photocoagulation system: design, construction and laboratory investigations. Trans Am Ophthalmol Soc 1968; 66: 827-904.

7 Zweng HC, Little HL, Peabody RR. Argon laser photocoagulation of diabetic retinopathy. Arch Ophthalmol 1971;86: 395-400.

8 Aiello LM, Beetham WP, Balodimos MC, Koncz L. Ruby laser photocoagulation in treatment of diabetic proliferating retinopathy preliminary report. In: Goldberg MF. Fine SL, eds.
Symposium on the Treatment of Diabetic Retinopathy. Bulletin 1890 of the Public Health Service, 1969: 437-63.

9 Fankhauser F, Lotmar W, Roulier A. Vergleichende Behandlung der diabetischen Retinopathie durch Photocoagulation mit dem Argon-laser und der Xenon-hochdruck Lampe. II Klinische Ergebnisse. Albrecht von Graefes Arch Klin Ophthalmol 1972; 184: 111-25.

10 McLean EB. Argon and xenon photocoagulation in the treatment of diabetic retinopathy. Trans Pac Coast Otoophthalmol Soc 1976; 57: 183-92.

11 Diabetic Retinopathy Study Research Group. Preliminary report on the effects of photocoagulation study. Am J Ophthalmol 1976; 81: 383-96.

12 Diabetic Retinopathy Study Research Group. Photocoagulation of proliferative diabetic retinopathy. Second report. Ophthalmology 1978; 85: 82-106.

13 Crick MD, Chignell AH, Shilling JS. Argon laser $v$ xenon arc photocoagulation in proliferative diabetic retinopathy. Trans Ophthalmol Soc UK 1978; 98: 170-1.

14 Wallow IH, Davis MD. Clinicopathologic correlation of xenon arc and argon laser photocoagulation. Procedure in human diabetic eyes. Arch Ophthalmol 1979; 97: 2308-15.

15 Hercules BL, Gayed II, Lucas SB, Jeacock J. Peripheral retinal ablation in the treatment of proliferative diabetic retinopathy: a three-year interim report of a randomised, controlled study using the argon laser. Br J Ophthalmol 1977; 61: 555-63.

16 Multicentre Photocoagulation Trial (co-ordinator Cheng $\mathrm{H}$ ). Proliferative diabetic retinopathy: treatment with Xenon arc photocoagulation. Br Med J 1977; i: 739-41.

17 Oosterhuis JA, Beintema MR, Lemkes HH, Nikkels R. Terpstra J. Photocoagulation treatment in diabetic retinopathy: a two-year pre- and five-year post-treatment study. Doc Ophthalmol 1979; 48: $101-62$.

18 Hamilton AC, Townsend C, Khoury D, Gould E, Blach RK. Xenon arc and argon laser photocoagulation in the treatment of diabetic disc neovascularisation: Part 1. Effect on disc vessels. visual fields, and visual acuity. Trans Ophthalmol Soc UK 1981; 101: 87-92.

19 Birch J, Hamilton AM. Xenon arc and argon laser photocoagulation in the treatment of diabetic disc neovascularisation. Part 2: Effect on colour vision. Trans Ophthalmol Soc UK 1981; 101: 93-9.

20 Oakley NW, Hill DW, Joplin GF. Kohner EM. Fraser TR. Diabetic retinopathy. I. The assessment of severity and progress by comparison with a set of standard fundus photographs. Diabetologia 1967; 3: 402-5.

21 Baker RT, Nelder JA. The GLIM svstem manual for Release 3. Numerical Alogarithims Group. 7 Banbury Road, Oxford: 1978. 